\title{
Analysis of potential impacts on coastal areas due to changes in wave conditions
}

\author{
J. P. Sierra • M. Casas-Prat
}

Received: 15 August 2013 / Accepted: 26 March 2014 / Published online: 23 April 2014

(C) The Author(s) 2014. This article is published with open access at Springerlink.com

\begin{abstract}
This study examines the main physical processes related to coastal and port engineering that could be altered by future changes in wave parameters as a consequence of climate change. To estimate the order of magnitude of the potential changes in these processes, several assumptions and simplifications are made and, in most cases, they are assessed by using simple, empirical state-of-the-art expressions. The studied processes are grouped in three categories according to whether they affect beaches, harbors or coastal structures in general. The changes in these processes are estimated as a function of the deepwater variations of the main wave parameters: wave height $\left(H_{0}\right)$, wave period $(T)$ and wave direction $\left(\theta_{0}\right)$. A moderate range of variation is assumed for these parameters at deep water ( \pm 10 or $\pm 20 \%$ in $H_{0}$ and its square root in $T$, and $\pm 10^{\circ}$ in $\theta_{0}$ ), taking into account recent studies of future wave projections. The results indicate that potential changes in wave height will strongly affect overtopping discharge, stability and scouring of rubble-mound structures and, to a lesser extent, siltation, wave transmission and longshore sediment transport. Changes in wave direction will affect longshore sediment transport in particular and, at a lower magnitude, processes related to port operability (agitation and siltation). Siltation is the only process affected significantly by changes in $T$ alone.
\end{abstract}

\section{Introduction}

Climate change has become a major focus of attention of the scientific community because of its potential hazards and impacts on our environment in the near future. In coastal areas, one of

Electronic supplementary material The online version of this article (doi:10.1007/s10584-014-1120-5) contains supplementary material, which is available to authorized users.

J. P. Sierra $(\varangle) \cdot$ M. Casas-Prat

Laboratori d’Enginyeria Marítima, Universitat Politècnica de Catalunya BarcelonaTech, Jordi Girona 1-3, Mòdul D1, Campus Nord, 08003 Barcelona, Catalonia, Spain

e-mail: joan.pau.sierra@upc.edu

M. Casas-Prat

e-mail: merce.casas@upc.edu

J. P. Sierra • M. Casas-Prat

Centre Internacional d'Investigació dels Recursos Costaners (CIIRC), Jordi Girona 1-2, Mòdul D1, Campus Nord, 08003 Barcelona, Catalonia, Spain 
the best-known consequences of the greenhouse effect and the resulting global warming is sealevel rise (SLR), mainly due to melting of ice sheets and thermal volume expansion (e.g. Pritchard and Vaughan 2007). Despite the great uncertainty regarding future SLR, numerous studies have estimated its impacts on coastal areas (e.g. Stive 2004; Nicholls and Cazenave, 2010).

Although coastal vulnerability assessments focus mainly on SLR, SLR is not the only physical process of concern to coastal communities. As pointed out by various authors (e.g. Bengtsson et al. 2006; Weisse and von Storch 2010), the greenhouse effect and the complex interactions of atmospheric processes may produce changes in near-surface wind and pressure patterns, which, in turn, can affect the pattern of another important coastal driver: the wave field.

Numerous studies have reported that changes in ocean wave climate are detectable (e.g. Aumann et al. 2008; Wang et al. 2009). Evidences suggest that the number, intensity and location of storms will change (e.g. Wang et al. 2004; Bengtsson et al. 2006; Lionello et al. 2008). Most of these studies have focused on changes in wave height, whereas little attention has been paid to changes in wave direction or wave period. These two parameters must not be neglected. Even in a situation of constant wave storminess magnitude, rotation of the mean wave direction may have severe consequences because most beach and harbor defense structures were designed assuming a permanent directional distribution of waves. This situation can become critical because a large percentage of coasts are already eroding (e.g. SánchezArcilla et al. 2011). Moreover, a higher frequency of coastal storms in the same direction as the harbor mouth could influence port operations by causing increased agitation (Casas-Prat and Sierra, 2012) and siltation. In addition, changes in wave period would affect propagation processes such as shoaling, refraction and diffraction, and therefore they could modify sediment transport patterns or wave penetration into harbors.

In recent years, a number of studies have analyzed the potential impacts on specific coastal areas of wave changes due to climate change, focusing in particular on coastal erosion (e.g. Coelho et al. 2009; Zacharioudaki and Reeve 2011; Casas-Prat and Sierra 2012) and harbor operability (Casas-Prat and Sierra 2010, 2012).

This paper provides an overview of the main impacts that changes in sea wave patterns produced by climate change can have on coastal areas. These impacts are analyzed simply and generically, and the expected effects on different processes are roughly quantified (obtaining orders of magnitude) as a guideline for further coastal impact assessment. Effects on other maritime areas of interest such as navigation and offshore structures are not analyzed. Moreover, the effect of SLR is not taken into account, although the combination of SLR with changes in sea wave patterns can enhance some negative impacts on coastal areas.

In Section 2, we identify the main physical coastal processes that can be affected by changes in the wave field and describe the followed methodology to quantify such affectation. In Section 3, we present the results thus obtained for each process. Finally, in Section 4, along with a discussion and inter-comparison of the results, we present the conclusions of this study.

\section{2. Methodology}

Table 1 presents the wave-induced processes and consequent coastal impacts identified and analyzed in this study that are relevant for coastal and port engineering, being their relationship with mean and extreme wave climates qualitatively indicated as high, low or none. The study therefore assesses physical impacts without examining socioeconomic or ecological effects.

The analysis is separated in three categories according to whether waves affect (sandy) beaches, harbors or coastal infrastructures in general. Overtopping and scouring, for example, 


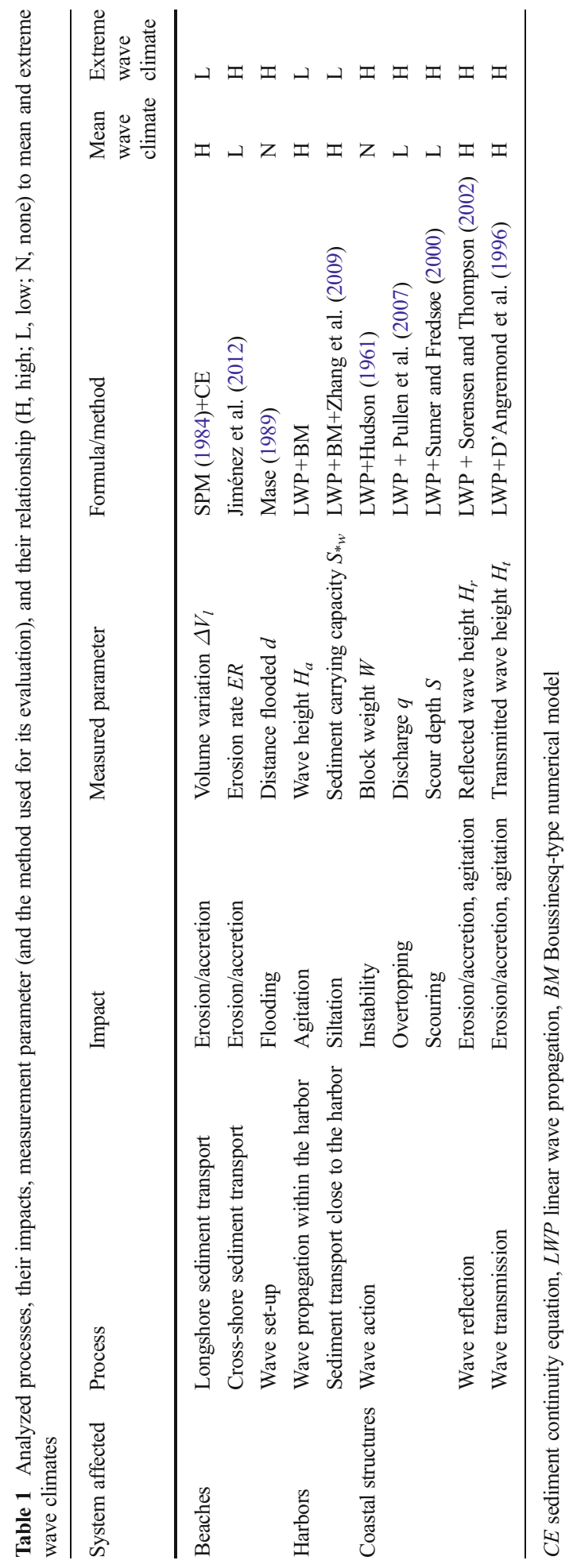


are problems that can affect either harbor breakwaters or coastal seawalls, but, owing to their singularity, harbors might face additional problems, like excessive agitation.

The effect of climate change on each system affected is assessed in terms of the relative variation of each process studied (using the measured parameter given in Table 1) as a function of relative variations in the following wave parameters at deep water (denoted by the subscript "0"): significant wave height $\left(H_{0}\right)$, peak wave period $(T)$ and mean wave direction $\left(\theta_{0}\right)$ (based on the linear wave theory we assume that $T$ remains the same as waves propagate).

For the sake of simplicity, we aim to evaluate the affectation of each wave parameter independently. However, since both $H_{0}$ and $T$ depend on wind speed (whose magnitude is predicted to vary in the future climate), both parameters are expected to change together often, particularly in areas where swell does not prevail. For this reason, in this study we consider that both parameters vary simultaneously as a result of wind influence. Nevertheless, Hemer et al. (2013) found that $T$ can increase while $H$ remains the same in areas where the swell component is important. Therefore, we examine the impacts due to variations in $i$ ) $H_{0}$ and $T$ together, $i$ i) $T$ alone and iii) $\theta_{0}$ alone. Indeed, the three parameters could all change together, such that their effects would superimpose nonlinearly, but this is not assessed in the present study.

The range of variation of $H_{0}$ is based on the work of Hemer et al. (2013), who projected maximum variations (at the global scale) in the mean $H_{0}$ of $10 \%$ by the end of the century. This rate, however, is expected to be higher in regard to the extreme wave climate due to the nonlinear relation between wave height and wind speed. Casas-Prat and Sierra (2013), for instance, obtained changes in the 50-year return period of $H_{0}$ of up to $20 \%$ on the Catalan coast by 2,100, but a lower maximum expected change in the median $H_{0}$ (around $10 \%$ ). Taking into account these results, the maximum variation of wave height due to climate change considered in this study is $\pm 20 \%$ for extreme waves and $\pm 10 \%$ for mean wave climate. Given that, we assume that $T$ varies at a rate equal to the square root of the (relative) wave height change (see Eqs. 1 and 2) because, for fully developed seas, $H_{0}$ is proportional to the square of wind speed while $T$ is proportional to wind speed (Resio et al. 2002).

$$
\begin{aligned}
& H_{0 F}=\kappa H_{0 P} \\
& T_{F}=\sqrt{\kappa} T_{P}
\end{aligned}
$$

where $\mathrm{K}$ is the ratio between future and present wave height. In this study, $0.8 \leq \mathrm{K} \leq 1.2$ (extreme waves) or $0.9 \leq \mathrm{K} \leq 1.1$ (mean wave climate), and the subscripts $F$ and $P$ indicate future and present conditions, respectively. The variation of $T$ alone (just Eq. 2) is only considered for those processes mainly affected by the mean wave climate (and therefore $0.9 \leq \kappa \leq 1.1$ ) because swell events are not the dominant feature during storm conditions.

Meanwhile, for the mean wave climate the variations due to $\theta$ are assessed as:

$$
\theta_{0 F}=\theta_{0 P}+\Delta \theta_{0}
$$

Where $\theta$ is measured as the angle between the wave front and the shoreline or structure orientation and $\Delta \theta$ is the variation between present and future conditions (limited to $\pm 10^{\circ}$ as obtained by Hemer et al. (2013)). For the extreme wave climate, the worst condition for the beach or structure, i.e. perpendicular incidence of the waves, is considered for both present and future situations (therefore, $\theta_{O P}=\theta_{O F}=0$ ).

The rate of change of the analyzed processes is computed analytically where possible, as a function of the rate of change $k$ of the driving wave climate. For several processes, however, this simple approach cannot be followed and it is necessary to involve also present/future wave parameters and/or structure characteristics. A range of case studies is considered to cover the 
most representative wave and structure parameters. To account for the variability introduced by such degree of uncertainty, the $90 \%$ confidence levels (as the 5 and 95 percentiles) of the rate of change of the analyzed processes are computed together with the mean value. Table 1 summarizes the methods and formulations used; for further details refer to the Supplementary Information.

\subsection{Potential impacts on beach dynamics}

It is well accepted that changes in ocean wave climate (location, frequency, direction and severity of ocean storms) will bring about changes in the locations and magnitudes of coastal erosion and accretion in the future (Stive et al. 2002). Additionally, with future changes in wave climate and water levels, coastal flood risk will increase, affecting the sustainability of coasts worldwide. In this paper, we examine the potential impacts of wave changes on sandy coasts, focusing on variations in both longshore sediment transport (LST) and cross-shore sediment transport (CST), as well as the flooding caused by the wave-induced run-up.

As waves approach the coast, they break and generate a long-shore current causing the LST. This process, driven by the mean wave climate, controls the long term beach dynamics and the patterns of erosion and accretion. We analyze the impact of wave changes on this process in terms of the volume variation of sediment (per unit length and unit time, $\Delta V_{l}$ ), which is governed by alongshore gradients in LST rates, here computed according to SPM (1984).

On the contrary, CST and beach flooding are mainly forced by the extreme wave climate, being relevant at event or seasonal time scales. CST governs the short term beach dynamics and encompasses both offshore and onshore transport. The impact on CST is assessed here by means of the wave contribution to the storm erosion potential $(E R)$, as defined by Jiménez et al. (2012). In turn, waves contribute to beach inundation due to the combination of the wave set-up and the wave swash caused by waves breaking in the nearshore. The impact is assessed in terms of the distance flooded $d$ (Mase, 1989).

\subsection{Potential impacts on ports}

Besides coasts, ports are the infrastructure most likely to be affected by changes in wave climate. Changes in wave conditions can affect the wave height pattern within harbors, as shown by Casas-Prat and Sierra $(2010,2012)$ for some ports on the Catalan coast. In this paper, we analyze the impact on two processes that are very important for port operability: agitation and siltation. Episodic extreme waves may affect these processes but the analysis is centered in the (persistent) mean wave climate, that controls the common (long-term) operational problems.

The agitation within a harbor depends not only on the wave parameters but also on port features and the surrounding environment: geometry, bathymetry, reflectivity of structures, etc. In other words, agitation is case-specific and each harbor has its own pattern. Because of the numerous factors involved, agitation cannot be simplified or estimated using a single formula. As a consequence, more complex tools such as numerical models, which require a large amount of case-specific information (e.g. harbor layout), must be used to study agitation. It is therefore impossible to obtain results that can be generalized and applied to all harbors. Nevertheless, in order to roughly estimate how changes in wave parameters can affect port agitation, we analyze wave propagation under changing wave parameters in a port with a simplified geometry. Such agitation is assessed by the mean wave height due to agitation inside the port $\left(H_{a}\right)$

In addition, many ports throughout the world suffer from considerable siltation, which entails expensive maintenance dredging. Winterwerp (2005) described the siltation rate as a 
function of a number of processes: horizontal entrainment, tidal filling, fresh/salt-driven density currents, warm/cold density currents and sediment-induced density currents. The siltation produced by any of these processes is basically affected by the sediment availability outside the harbor and the water movements that can mobilize such sediment towards the inside. In this study, we focus on the second aspect only considering the wave influence and therefore neglecting other effects. We assess the siltation in terms of the (wave) sediment carrying capacity, $S_{W}$ (Zhang et al. 2009). We consider therefore the sediment that could potentially enter the harbor given certain wave conditions, assuming unlimited supply of sediment. Such wave conditions are derived from the wave height fields near the harbor entrance obtained with the simulations previously carried out to evaluate the agitation problem.

\subsection{Potential impacts on coastal structures}

We also examine the potential impacts of changes in wave parameters on a series of processes related to coastal structures: stability, overtopping, scouring, wave reflection and wave transmission. These processes can affect structures located either on coasts or in harbors and are principally controlled by the extreme wave climate, except for the last two, for which the mean wave climate is also relevant. In order to compute the impact associated to each process for present and future conditions, additional parameters are involved in the computation, basically those related with the structure layout.

The first process studied is structure stability. We consider the stability of common rubblemound breakwaters, whose design is based on the computation of the weight $(W)$ of the armor units in the primary cover layer. In this case, instead of studying the direct impact on structure stability, we assess the necessary changes in the dimensioning of the structure, i.e. in terms of $W$. We use Hudson (1961)'s empirical formula, in which $W$ depends on the design wave height at the structure toe $\left(H_{S}\right)$, obtained from extreme wave climate analysis.

Another analyzed process is structure overtopping. Overtopping occurs when the wave runup obtained under extreme wave conditions exceeds the structure freeboard. The amount of allowable overtopping depends on the function of the particular structure. Certain functionssuch as berth for vessels, roadways, storage areas or buildings located just behind the breakwater - put restrictions on the allowable overtopping discharge (Burchart and Hughes 2003). This discharge depends mainly on the water level and the nearshore wave height, although only the latter is considered in this study. To obtain the overtopped discharge, the empirical expression of Pullen et al. (2007) is used.

Scouring, the removal of granular bed material by hydrodynamic forces in the vicinity of coastal structures, is another process analyzed here. This phenomenon can lead either to partial damage or, in some cases, to the complete failure of all or portions of a structure (Burchart and Hughes 2003) and is particularly sensitive to extreme waves. To compute the scouring at the toe of a rubble-mound breakwater we use Sumer and Fredsøe (2000) formula that serves to estimate the scour depth $(S)$.

In addition, when a wave encounters an obstacle such as a coastal structure, part of the wave energy is diverted and propagated in another direction causing wave reflection. This reflected wave can transport energy to unwanted areas, such as the interior of a harbor (increasing the agitation within it) or a beach (producing more erosion). Therefore, changes in reflected wave heights can cause adverse effects in coastal areas that must be foreseen. This process is sensitive to both mean and extreme wave climates. The empirical equation obtained by Sorensen and Thompson (2002) from laboratory experiments is used to estimate the reflected wave height $\left(H_{r}\right)$.

Finally, when waves interact with a structure, a portion of their energy may pass over and through the structure, generating waves behind it. This process is known as wave transmission. 
Like in wave reflection, both the mean and extreme wave climates are important in the study of this process, which is performed using the transmitted wave height $\left(H_{t}\right)$. Wave transmission is particularly important in low-crested structures, especially rubble-mound ones, which have greater porosity. To compute wave transmission we use also an empirical expression: D’Angremond et al. (1996).

\section{Results}

\subsection{Changes in wave height and period}

In this Section, we analyze the changes in the processes mentioned in Section 2 produced by variations of $H_{0}$ and $T$ by a factor of $\kappa$ and $\kappa^{1 / 2}$ respectively. Figures 1 and 2 show the results concerning the mean and extreme wave climate, respectively, when $H$ and $T$ vary together. In the case of coastal structures, they are divided into coastal and port environments, which typically have different dimensions and configurations. Variable $P$ in the y-axis denotes generically "parameter estimated", being different for each process (see Table 1).

Figure 1a compares the results obtained for LST, agitation and siltation. Siltation and agitation exhibit, respectively, the largest and lowest range of variation.

Siltation is very sensitive to changes in $H$ and $T$. The ratio of future and present $S_{W}$ is considerably larger than $\kappa$, ranging on average from -37 to $+35 \%$. On the other hand, the other relevant process related to port operability (agitation) show on average a rate of increase/ decrease similar to $\mathrm{K}$. A $10 \%$ increase (decrease) in $H_{0}$ (and the corresponding decrease in $T$ ) yields, on average, a $12 \%(13 \%)$ increase (decrease) in $H_{a}$. For both siltation and agitation, these changes are averages over the 240 simulations performed. The $90 \%$ confidence levels are also shown in Fig. 1a and Table 2 indicating a higher level of uncertainty for siltation.

Eroded beach volume caused by LST varies by a factor of $\kappa^{5 / 2}$. For the analyzed range of change $(0.9<\kappa<1.1)$, this means that the ratio of future and present $\Delta V_{l}$ varies between -23 and $+27 \%$ (Fig. 1a).
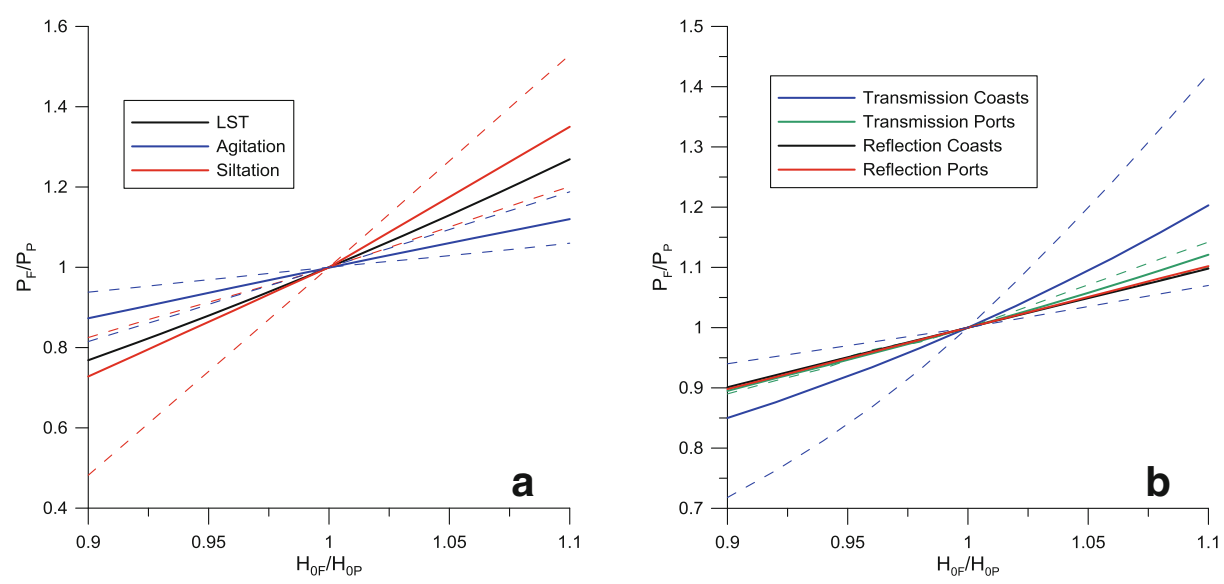

Fig. 1 Changes in processes driven by mean wave climate due to variations in wave height and period. (a) LST, agitation and siltation. (b) Reflection and transmission. The vertical axis measures the ratio of future and present values of the assessed parameters (see Table 1). Dashed lines indicate the $90 \%$ confidence intervals. In the case of reflection the confidence intervals are not plotted because they overlap the corresponding average values 
Fig. 2 Changes in processes driven by extreme wave climate due to variations in wave height and period. (a) CST, flooding,

overtopping, stability and scouring in coastal infrastructures. (b)

Overtopping, stability and scouring in ports. (c) Reflection and transmission. The vertical axis measures the ratio of future and present values of the assessed parameters (see Table 1). Dashed lines indicate the $90 \%$ confidence intervals. In the case of reflection the confidence intervals are not plotted because they overlap the corresponding average values
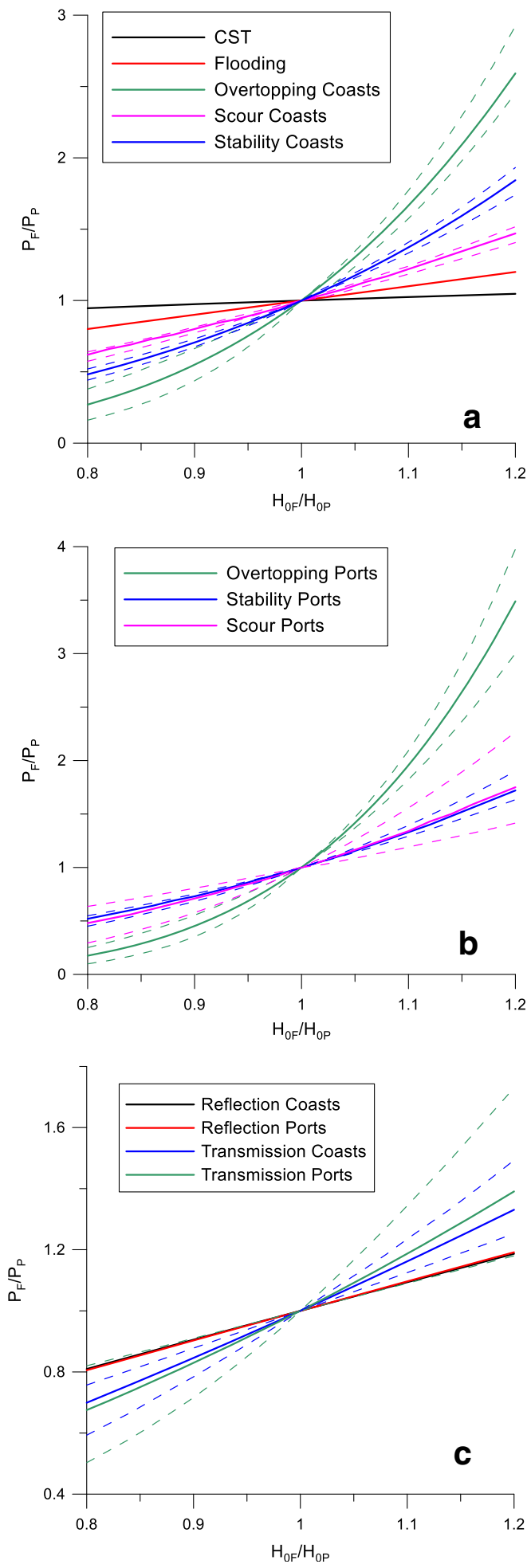


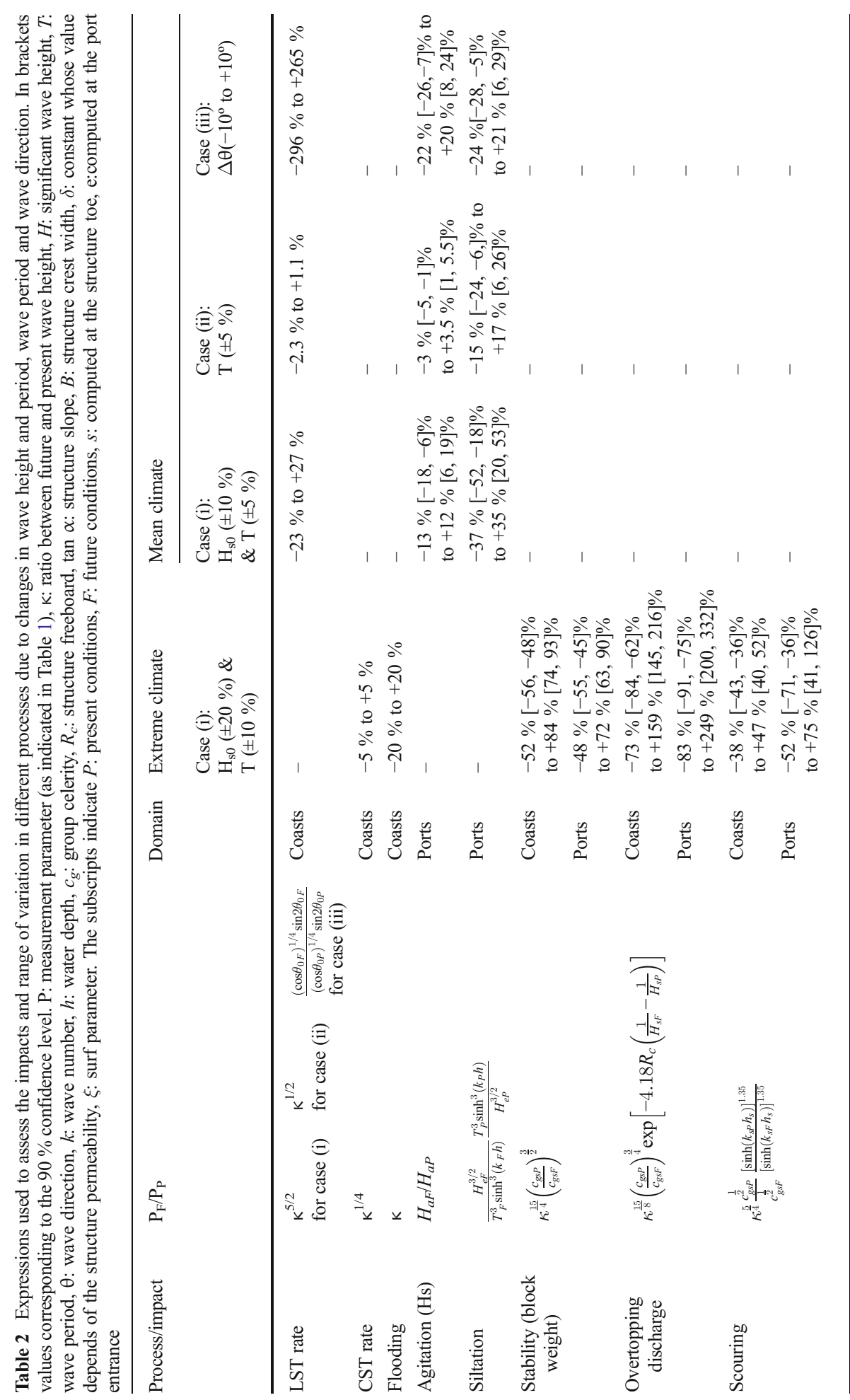




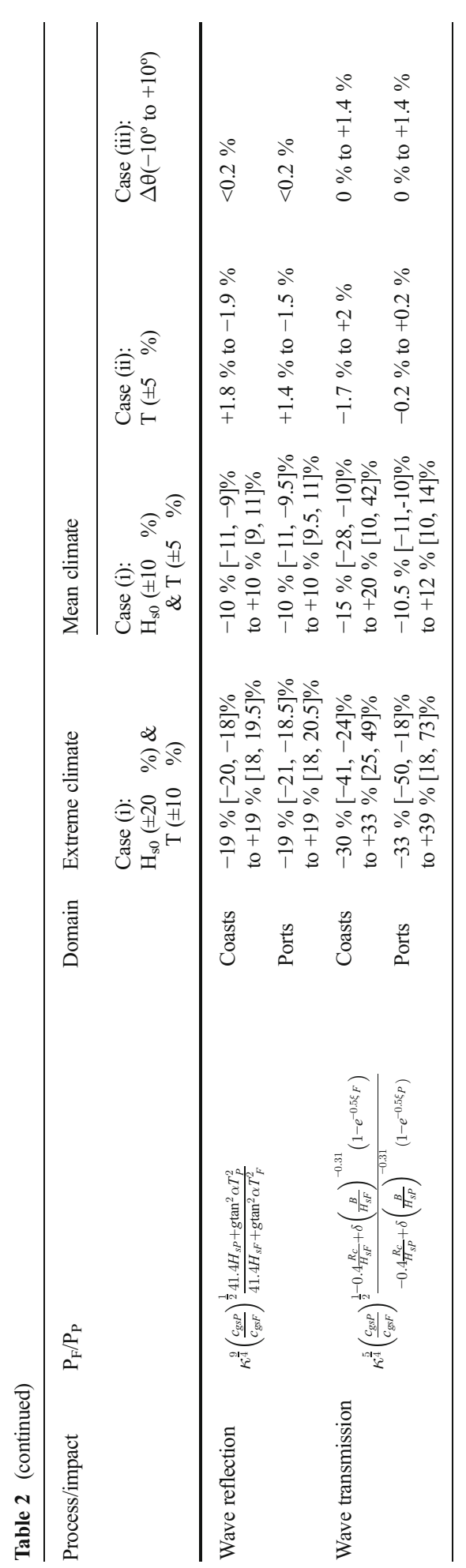


In Fig. 1b, the changes in the reflection and transmission wave heights due to changes in $H_{0}$ and $T$ for mean wave climate are shown separately for coastal and harbor structures. The variations in $H_{r}$ are practically the same as those in the incident wave height because the reflection coefficient $K_{r}$ (the rate between incident and reflected $H$ ) does not significantly vary as a function of $H$ and $T$. Even the $90 \%$ confidence levels hardly differ from this pattern. Differences between the two types of structure are barely noticeable. In contrast, for $H_{t}$, the rate of variation depends on the environment considered. $H_{t}$ undergoes smaller changes $(-10$ to $12 \%$ on average, similar to those of $\left.H_{r}\right)$ for port structures $(-15$ to $+20 \%$ on average for coastal ones) due to the greater freeboards and the assumption that such structures are impermeable and allow a low transmission of wave energy. Moreover, transmission in coastal structures has associated a higher level of uncertainty.

When $T$ changes alone (case ii of Table SM1) the analysis of the processes controlled by the mean wave climate indicates that only siltation is significantly affected $(-15$ to $+17 \%$ on average). The other processes experience variations at a rate lower than $3 \%\left(\leq \kappa^{1 / 2}\right)$.

Figure 2 a sets against results corresponding to beach processes driven by extreme wave climate and affecting coastal areas: CST, flooding and structure overtopping, stability and scouring. Figure $2 \mathrm{~b}$ shows the results for the last three processes affecting ports. CST and beach flooding have the lower rate of variation, especially CST that varies by a factor of $\kappa^{1 / 4}$ : $20 \%$ increase in $H_{0}$ causes a $5 \%$ increase in $E R$. Therefore, although the change of extreme $H_{0}$ is supposed to be higher than for the mean $H_{0}$, changes in CST are expected to be lower than changes in LST, in terms of the parameters studied.

The flooded distance varies linearly with respect to relative variations of $H_{0}$. Therefore, the potential impacts on coastal flooding due to higher and longer waves are of the same order as the ratio of increase in wave height ( $\mathrm{K}$ ), although their main effect will probably be to enhance the consequences of storm surges and SLR.

Concerning stability, we see that the ratio between the necessary weight of a rubble-mound structure under future and present conditions is slightly greater for coastal structures than for port breakwaters (Figs. 2a and b). On average, a $20 \%$ increase in $H_{0}$ would require stones up to $84 \%$ (coastal structures) or $72 \%$ (port breakwaters) heavier. If the same units were kept in the armor layer of the breakwater, they might be moved from their original position or even removed from their location, thereby generating instability and eventually the destruction of the breakwater due to the increase of $H$. On the contrary, waves with a $20 \%$ smaller $H_{0}$ would need on average blocks up to $52 \%$ (coasts) or $48 \%$ (ports) lighter, so the stability of the structure would be increased in this case.

Figures $2 \mathrm{a}$ and $\mathrm{b}$ also present the average ratio (and the $90 \%$ confidence levels) between future and present overtopping, the process that mostly varies with changes in the extreme $H$ (and $T$ ). Increases of 10 and $20 \%$ (in $H_{0}$ ) can induce on average, respectively, overtopping discharges 67 and $159 \%$ greater than the present values in the case of coastal structures and 96 and $249 \%$ greater in the case of port breakwaters. Although coastal structures have lower freeboards, the ratio of overtopping is greater for port structures probably because coastal structures are located in shallower waters and the largest waves - those which produce the largest overtopping discharges - break before reaching such structures. The large sensitivity of overtopping to $H_{0}$ increases will be particularly critical in structures that already have overtopping problems. Moreover, in the context of climate change, we must take into account that these potential changes will most likely be accompanied by SLR, which in turn will reduce the crest freeboard of coastal structures, further increasing overtopping discharges.

Scouring is the last process plotted in Figs. 2a and b. As expected, it will be lower (greater) for future lower (greater) $H$ and $T$. It has been found that this variation is greater (in relative value) as the ratio between water depth and wave period (or wave length) increases (see 
Figure SM4). This can be explained by the fact that, for relatively large depths - typically associated with ports rather than with coastal structures - the absolute value of scouring is low and, therefore, even small absolute variations can give rise to large rates of variation. Consequently, changes in scouring between future and present conditions are greater for port breakwaters ( +75 and $-52 \%$ on average) than for coastal structures $(+47$ and $-38 \%$ on average). The processes with a higher level of uncertainty (as shown by $90 \%$ confidence levels) are overtopping and scouring (ports).

Finally, Fig. 2c shows the same processes as Fig. $1 \mathrm{~b}$ but affected by extreme wave climate. Apart from a larger range of variation $(0.8<\mathrm{k}<1.2)$, there are differences in the wave climate for the present situation, that obviously consider more energetic waves than for the mean wave climate. These variations barely affect the pattern of change of $H_{r}$, that varies at the similar rate as the incident wave height. In the case of $H_{t}$, however, different results are obtained compared to the mean wave climate. In average, port structures undergo larger changes in $H_{t}$. This could be explained by the fact that, because these structures are located at greater depths, they are exposed to higher waves and, as a consequence, greater amounts of wave energy are transmitted to the lee side of the structure. By contrast, coastal structures are located in shallower waters and the largest waves break before reaching the structure. From Fig. 2c we can derive that a $20 \%$ decrease in $H_{0}$ can cause on average decreases of up to $30 \%$ (coasts) or $33 \%$ (ports) in $H_{t}$ while a $20 \%$ increase in $H_{0}$ can give rise on average to increases of up to $33 \%$ (coasts) or $39 \%$ (ports) in $H_{t}$, with high levels of uncertainty for large values of $\mathrm{k}$

\subsection{Changes in wave direction}

In this section the processes that suffer from variations in the wave direction are assessed (case iii of Table SM1). They are those affected by the mean wave climate: LST, agitation, siltation, wave reflection and wave transmission. As seen later on, the least affected are the last two processes whereas the largest variations are encountered for LST (for nearly perpendicular waves).

In Fig. 3 the variations in LST rates are plotted as a function of $\Delta \theta_{0}$ for different angles for the present conditions $\left(\theta_{0 P}\right)$. We can see that, for a given value of $\Delta \theta_{0}$ and for waves with less oblique incidence $\left(\theta_{0 P}<45^{\circ}\right)$, the smaller the value of $\theta_{0 P}$, the greater the changes in LST rates (the smallest variations are obtained for $\theta_{0 P}=45^{\circ}$ ). On the contrary, for highly oblique waves $\left(\theta_{0 P}>45^{\circ}\right)$, the larger the value of $\theta_{O P}$, the greater the changes, but these changes are less pronounced than in the case of $\theta_{0 P}<45^{\circ}$. Note that, for a $45^{\circ}$ angle, any change in wave direction produces only small relative changes in LST rates because LST rates have their highest values at this angle. On the contrary, for $90^{\circ} / 0^{\circ}$ angles (incidence parallel/perpendicular to the shoreline), the present LST rate is zero, so the relative changes (according to Eq. SM8) would be infinite. As explained in Supplementary Information, these variations in LST rates coincide with the changes in beach volume.

Figure 4 a shows how changes in agitation are conditioned to $\theta_{0 P}$. For a given value of $\Delta \theta_{0}$, the waves with the most direct incidence towards the mouth of the harbor (positive $\theta_{0 P}$ ) are associated with the largest changes in the agitation coefficients. In general, a $10^{\circ}$ decrease in wave angle entails a decrease of up to $22 \%$ in the average $H_{a}$, while a $10^{\circ}$ increase in wave angle entails an increase of up to $20 \%$ in the average $H_{a}$. Note that these variations are higher than the ones obtained when varying the wave height and period.

Figure $4 \mathrm{~b}$ presents for the same cases considered for Fig. 4a, how siltation is affected by changes in wave direction. A singular pattern for high negative angles (less incidence towards the mouth) is obtained, since siltation increases in value at a greater rate than for positive angles. This is probably due to the lower absolute values of siltation obtained for large negative 


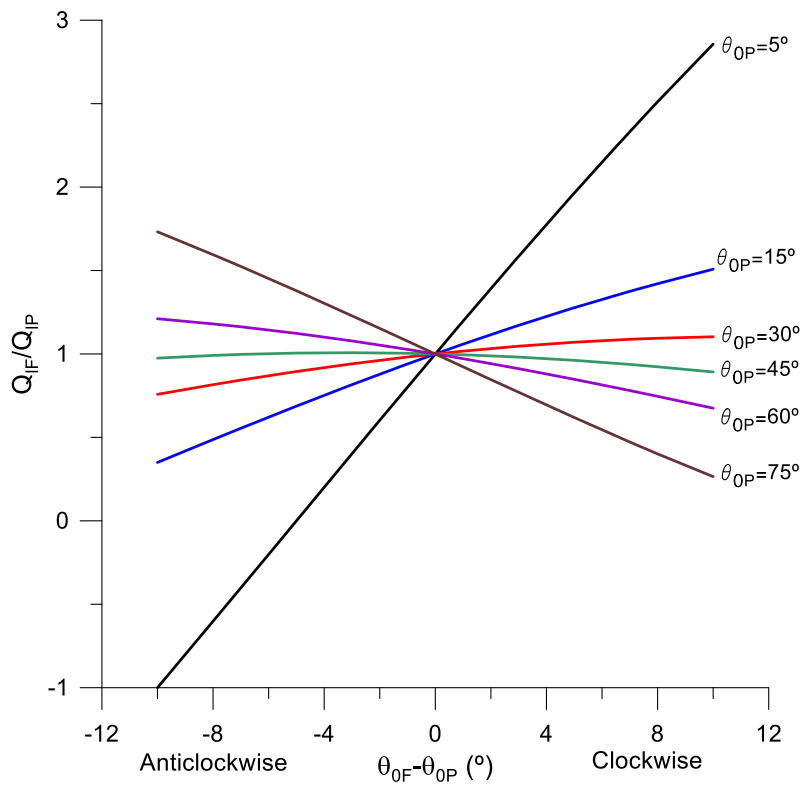

Fig. 3 Changes in longshore sediment transport rates as a function of changes in wave direction

angles, because a small increase in absolute magnitude can cause large increases in relative value.

A similar analysis is performed in order to estimate the changes on wave reflection. We found that variations in $K_{r}$ (and therefore in $H_{r}$ ) are negligible, with values lower than $0.2 \%$. With also relatively similar low rates, the ratio of $H_{t}$ ranges from 0 to $1.4 \%$ for coastal structures, while this value is negligible $(<0.1 \%)$ for port structures. The angle of wave attack has no or only marginal influence on $K_{t}$ for rubble-mound breakwaters (the most common type), as pointed out by van der Meer et al. (2005). Therefore, for rubble-mound structures it can be assumed that $H_{t}$ does not change if the wave direction at the structure varies.
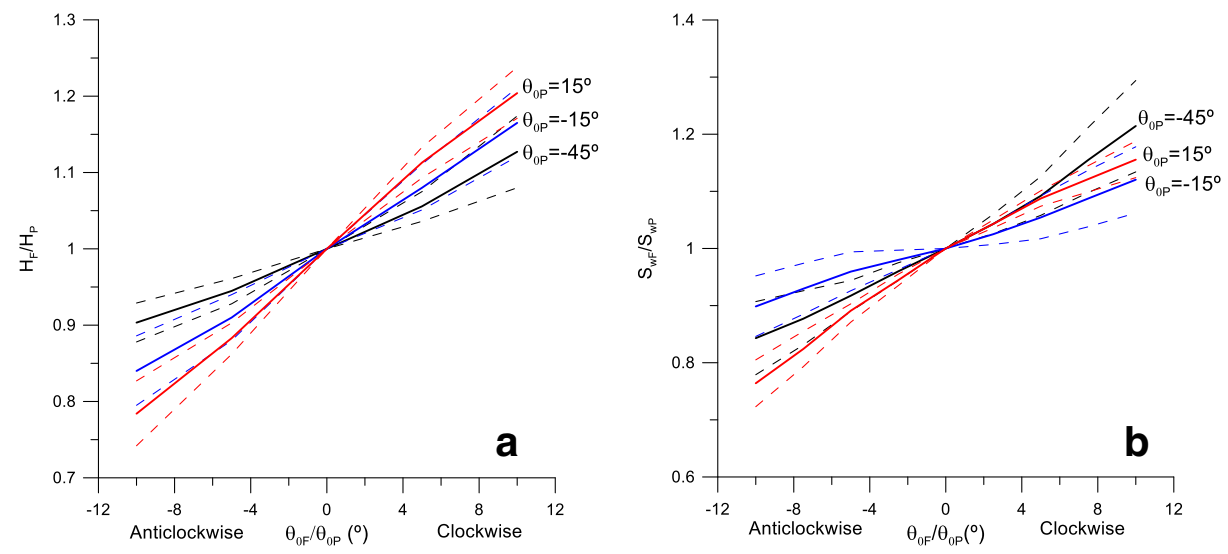

Fig. 4 (a) Changes in wave height within the harbor due to variations in wave angle. (b) Changes in the siltation rate due to variations in wave angle. In both cases changes are estimated for different present angles. Dashed lines indicate the $90 \%$ confidence intervals 
Nevertheless, since we are assuming changes in deepwater wave direction, we must account for changes in the propagated wave height from deep water to the structure due to the different wave direction, which leads to the aforementioned slight changes.

\section{Discussion and conclusions}

The main objective of this paper was first to identify the physical processes in coastal areas most affected by changes in wave parameters, and second, to analyze the degree of dependence of these processes on the corresponding driving wave parameters. We have therefore reviewed the main physical processes relevant to coastal/port engineering that could be altered by future variations in wave climate as a consequence of climate change. An order of magnitude of the changes in these processes has been estimated as a function of the variations (at deep water) in the main wave parameters that control wave propagation: wave height $\left(H_{0}\right)$ and period $(T)$ together, due to their close relationship, $T$ alone (changes generated by the swell influence) and wave direction $\left(\theta_{0}\right)$. A moderate range of variation is assumed for these parameters $( \pm 10$ or $\pm 20 \%$ in $H$ for mean and extreme wave climate, respectively, its square root in $T$ and $\pm 10^{\circ}$ in $\theta$ ). As mentioned above, $H, T$ and $\theta$ could change simultaneously, so their impact would be superimposed in a nonlinear way not estimated in this study.

Due to the complexity of the analyzed processes, a number of simplifications and assumptions has been made in order to perform this study. Therefore, results shown in Table 2 should be taken as an indication and properly calibrated for the zone where the impact assessment is carried out. Nevertheless, the results still give us a general idea of the most affected physical coastal processes given a future wave climate change scenario which can be very useful in the prioritization of further detailed coastal impact studies. As expected, for the processes that take into account several case studies, the level of uncertainty increases with the magnitude of the changes in wave parameters.

From Table 2, we conclude that changes in $H_{0}$ and $T$ will strongly affect overtopping discharge, stability and scouring of rubble-mound structures and, to a lesser extent, siltation, wave transmission, LST and port agitation. Beach flooding and wave reflection would change at the same rate as wave height, while CST would change at lower rates than wave height.

The changes in wave period alone affect significantly port siltation $(-15$ to $+17 \%)$ in agreement with the general understanding that long period waves increase suspended sediment concentration transported by waves (Zhang et al. 2009), while the other processes vary at a lower rate than $T$ itself $(\leq \pm 3 \%)$.

As for the wave period, the variations produced by changes in wave direction have been studied only in processes dominated by the mean wave climate. Among these processes, the one most affected by potential changes in wave direction is the LST rate, which could undergo huge variations in magnitude. Processes related to port operability (agitation and siltation) are also sensitive to changes in wave direction. By contrast, the effects of changes in wave direction on wave reflection and wave transmission are almost negligible in magnitude.

The main conclusion of this study is that plausible changes in wave conditions due to climate change could greatly affect both harbors and coasts due to the nonlinear relations governing the processes studied. In the case of harbors, increases in wave height could force port authorities to make large investments to reinforce breakwaters against instability or to increase their freeboard to limit overtopping discharge. Moreover, berms or other defense methods could become necessary to reduce structure scouring that could result in damage, or even destruction, of breakwaters. Finally, other possible consequences of changes in wave conditions (in particular, wave direction) could make it necessary to design new structures or 
even make major changes to port layout (at considerable economic cost) in order to avoid excessive siltation or agitation within the harbor.

Modifications in wave conditions could involve major changes in beach dynamics due to significant variations in LST rates and, consequently, the need to take major coastal defense measures (e.g. beach fills, new coastal structures). As in the case of ports, coastal defense structures could be affected by instability, overtopping and scouring. This could make it necessary to reinforce these structures or build berms to prevent them from being damaged or collapsing. It might also be necessary to increase the freeboard of seawalls in order to protect maritime promenades or seaside infrastructure (roads, railways, buildings) from overtopping. All of these measures would obviously entail considerable costs.

Since even small changes in wave climate can lead to large impacts on coastal processes, it is necessary to raise awareness among coastal and port authorities and other stakeholders about the potential impacts of climate change on coastal areas. These impacts include not only those caused by SLR but also those driven by wave climate. The identification of potential future vulnerabilities and risks can facilitate the process of designing appropriate adaptation responses.

Finally, we want to stress that our impact assessment has only involved physical parameters. To perform an integrated assessment of these impacts and the risk associated to coastal areas, it would be necessary to take socioeconomic aspects into account (e.g. Arnell et al. 2004; Nicholls et al. 2008) that would also facilitate the inter-comparison between different impacts.

Acknowledgments The work described in this publication was funded by the European Union's Seventh Framework Programme through the grant to the budget of the Collaborative Project RISES-AM-, Contract FP7ENV-2013-two-stage-603396. The second author was enjoying a PhD grant from the Spanish Ministry of Education.

Open Access This article is distributed under the terms of the Creative Commons Attribution License which permits any use, distribution, and reproduction in any medium, provided the original author(s) and the source are credited.

\section{References}

Arnell NW, Livermore MJL, Kovats S, Levy PE, Nicholls R, Parry ML, Gaffin SR (2004) Climate and socioeconomic scenarios for global-scale climate change impact assessments: characterizing the SRES storylines. Glob Environ Chang 14:3-20

Aumann H, Ruzmaikin A, Teixeira J (2008) Frequency of severe storms and global warming. Geophys Res Lett 35, L19805

Bengtsson L, Hodges KI, Roeckner E (2006) Storm tracks and climate change. J Clim 19:3518-3543

Burchart HF, Hughes SA (2003). Coastal engineering manual. Part VI, chapter V: fundaments of design. USACE, p. 316

Casas-Prat M, Sierra JP (2010) Trend analysis of wave storminess: wave direction and its impact on harbour agitation. Nat Hazard Earth Syst Sci 10:2327-2340

Casas-Prat M, Sierra JP (2012) Trend analysis of wave direction and associated impacts on the Catalan coast. Clim Change 115:667-691

Casas-Prat M, Sierra JP (2013) Projected future wave climate in the NW Mediterranean Sea. J Geophys Res Oceans 118:3548-3568

Coelho C, Silva R, Veloso-Gomes F, Taveira-Pinto F (2009) Potential effects of climate change on northwest Portuguese coastal zones. ICES J Mar Sci 66:1497-1507

D’Angremond K, van der Meer JW, de Jong RJ (1996) Wave transmission at low crested structures. Proceedings of the 25th international conference on coastal engineering, Orlando, FL, USA, pp 2418-2427 
Hemer MA, Fan Y, Mori N, Semedo A, Wang XL (2013) Projected change in wave climate from a multi-model ensemble. Nat Clim Chang 3:471-476

Hudson RY (1961) Laboratory investigation of rubble mound breakwaters. Trans Am Soc Civil Eng 126, Pt IV Jiménez JA, Sancho-García A, Bosom E, Valdemoro HI, Guillén J (2012) Storm-induced damages along the Catalan coast (NW Mediterranean) during the period 1958-2008. Geomorph 143-144:24-33

Lionello P, Cogo S, Galati MB, Sanna A (2008) The Mediterranean surface wave climate inferred from future scenario simulations. Glob Planet Chang 63:152-162

Mase H (1989) Random wave runup height on gentle slope. J Waterw Port Coast Ocean Eng 115:649-661

Nicholls RJ, Cazenave A (2010) Sea-level rise and its impact on coastal zones. Science 328:1517-1520

Nicholls RJ, Wong PP, Burkett V, Woodroffe CD, Hay J (2008) Climate change and coastal vulnerability assessment: scenarios for integrated assessment. Sustain Sci 3:89-102

Pritchard HD, Vaughan DG (2007) Widespread acceleration of tidewater glaciers on the antarctic peninsula. J Geophys Res 112:F03S29

Pullen T, Allsop NWH, Bruce T, Kortenhaus A, Scüttrumpf H, van der Meer JW (2007) EurOtop wave overtopping of sea defences and related structures - assessment manual, p. 193

Resio DT, Bratos SM, Thompson EF (2002) Meteorology and wave climate, in coastal engineering manual, Part II, Chapter 2, $72 \mathrm{p}$

Sánchez-Arcilla A, Mósso C, Sierra JP, Mestres M, Harzallah A, Senouci M, El Raey M (2011) Climate drivers of potencial hazards in Mediterranean coasts. Reg Environ Chang 11:617-636

Stive MJF (2004) How important is global warming for coastal erosion? Clim Change 64:27-39

Stive MJF, Aarninkhof SGJ, Hamm L, Hanson H, Larson M, Wijnberg KM, Nicholls RJ, Capobianco M (2002) Variability of shore and shoreline evolution. Coast Eng 47:211-235

Sorensen R, Thompson EF (2002) Harbour hydrodynamics, in coastal engineering manual. Part II, Chapter 7:91

SPM (1984) Shore protection manual. 4th ed., 2 Vol, U. S. army engineer waterways experiment station, U. S. government printing office, Washington, DC

Sumer BM, Fredsøe J (2000) Experimental study of 2D scour and its protection at a rubble mound breakwater. Coast Eng 40:59-87

Van der Meer JW, Briganti R, Zanuttigh B, Wang B (2005) Wave transmission and reflection at low-crested structures: design formulae, oblique wave attack and spectral change. Coast Eng 52:915-929

Wang X, Swail V, Zwiers F, Zhang X, Feng Y (2009) Detection of external influence on trends of atmospheric storminess and northern oceans wave heights. Clim Dyn 32(2):189-203

Wang X, Zwiers F, Swail V (2004) North Atlantic ocean wave climate change scenarios for the twenty-first century. J Clim 17:2368-2383

Weisse R, von Storch H (2010) Marine climate and climate change. Storms, wind waves and storm surges. Springer, Praxis Publishing, Chichester

Winterwerp JC (2005) Reducing harbor siltation. I: Methodology. J Waterw Port Coast Ocean Eng 131:258-266

Zacharioudaki A, Reeve DE (2011) Shoreline evolution under climate change wave scenarios. Clim Change 108: 73-105

Zhang Q-E, Yan B, Wai OWH (2009) Fine sediment carrying capacity of combined wave and current flows. Int J Sed Res 24:425-438 